Jurnal Keperawatan Silampari

Volume 5, Nomor 1, Desember 2021

e-ISSN: 2581-1975

p-ISSN: 2597-7482

DOI: https://doi.org/10.31539/jks.v5i1.2344

\title{
PENGALAMAN PERAWAT YANG MENGALAMI TINDAK KEKERASAN OLEH KLIEN SKIZOFRENIA
}

\author{
Muhammad Amin ${ }^{1}$, Susilawati ${ }^{2}$, Wulan Angraini ${ }^{3}$ \\ Universitas Muhammadiyah Bengkulu ${ }^{1,2,3}$ \\ m.amin@umb.ac.id ${ }^{1}$
}

\begin{abstract}
ABSTRAK
Penelitian ini bertujuan untuk mengetahui bagaimana pengalaman perawat yang mengalami tindak kekerasan oleh klien skizofrenia. Jenis penelitian yang digunakan dalam penelitian ini adalah kualitatif yaitu suatu jenis penelitian yang bermaksud untuk menjelaskan dan memberi pemahaman dan interprestasi tentang berbagai perilaku dan pengalaman manusia (individu) dalam berbagai bentuk. Hasil penelitian menghasilkan beberapa tema yaitu bentuk kekerasan, kondisi pasien, tindakan pencegahan, keadaan perawat ketika mendapatkan kekerasan, kondisi kesehatan perawat dan waktu pasien mengamuk. Simpulan, kekerasan yang pernah dialami oleh perawat adalah dipukul, ditarik, dilempar menggunakan tempat makan dan juga diludahi. Kondisi pasien yang melakukan tindakan kekerasan adalah halusinasi pasien sedang timbul, pasien sedang labil dan obatnya tidak diminum.
\end{abstract}

Kata Kunci: Pengalaman Perawat, Skizofrenia, Tindakan Kekerasan

\begin{abstract}
This study aims to determine how the experience of nurses who experience acts of violence by schizophrenic clients. The type of research used in this research is qualitative, which intends to explain and provide understanding and interpretation of various behaviors and experiences of humans (individuals) in multiple forms. The study results produced several themes, namely the form of violence, the condition of the patient, preventive measures, the state of the nurse when receiving violence, the health condition of the nurse, and the time the patient was angry. In conclusion, the violence experienced by nurses was being hit, pulled, thrown using a food holder, and spat on. The patient's condition who commits acts of violence is that the patient's hallucinations are occurring, the patient is unstable, and the medicine is not taken.
\end{abstract}

Keywords: Nurse Experience, Schizophrenia, Violence

\section{PENDAHULUAN}

Gangguan jiwa suatu ketidakberesan kesehatan dengan manifestasi psikologis atau perilaku terkait dengan penderitaan yang nyata dan kinerja yang buruk, dan disebabkan oleh gangguan biologis, sosial, psikologis, genetik, fisis, atau kimiawi (Andri et al., 2019; Kurniawan, 2016). WHO (2018) mengatakan bahwa gangguan jiwa terdiri dari berbagai masalah dengan berbagai gejala yang berbeda. Namun pada umumnya ditandai oleh beberapa kombinasi perubahan pada pikiran, emosi, perilaku, dan hubungan abnormal dengan orang lain. WHO juga berpendapat bahwa Skizofrenia, depresi, retardasi mental, dan kelainan akibat penyalahgunaan obat terlarang termasuk kedalam gangguan jiwa. 
Berdasarkan data Riset Kesehatan Dasar (Riskesdas) tahun 2018 bahwa 7 dari 1000 rumah tangga terdapat anggota keluarga dengan skizofrenia/psikosis. Gangguan jiwa berat sering juga disebut dengan skizofrenia (Riskesdas, 2018). Skizofenia di Indonesia mengalami peningkatan jumlah skizofrenia cukup banyak, diperkirakan prevalensi dengan skizofrenia di Indonesia pada tahun 2013 adalah 1.728 orang. Jumlah penderita skizofrenia di Indonesia ini terkait dengan tingginya stress yang muncul di daerah perkotaan. Selain itu prevalensi gangguan jiwa mental pada penduduk umur lebih 15 tahun di Indonesia secara nasional adalah 6.00/0 (37.728 orang dari subjek yang dianalisis) (Riskesdas, 2018).

Berdasarkan data yang diperoleh dari Rumah Sakit Khusus Jiwa Provinsi Bengkulu pada tahun 2017, total kunjungan maupun rawat inap maupun rawat jalan dirumah sakit, puskesmas dan sarana pelayanan kesehatan lain adalah sebanyak 713.666 kunjungan. Dari total kunjungan itu dilaporkan sebanyak 8.233 merupakan kunjungan ganguan jiwa. Menurut data rumah sakit jiwa terdapat peningkatan jumlah pasien jiwa dari tahun ketahun baik yang berobat maupun rawat jalan dan rawat inap jumlah pasien kambuh pada tahun 2016 sebanyak 1.025 orang sedangkan 2017 sebanyak 1.124 orang (Dinas Kesehatan Kota Bengkulu, 2018).

Skizofrenia sebagai penyakit neurologis yang mempengaruhi persepsi klien, cara berpikir, bahasa, emosi, dan perilaku sosialnya, 450 juta orang diseluruh dunia mengalami gangguan mental, sekitar $10 \%$ orang dewasa mengalami gangguan jiwa saat ini dan $25 \%$ penduduk diperkirakan akan mengalami gangguan jiwa pada usia tertentu selama hidupnya. Usia ini biasanya terjadi pada dewasa muda antara usia 18-21 tahun (Cheruvu \& Chiyaka, 2019; WHO, 2017).

Skizofrenia merupakan diagnosa medis yang banyak ditemukan pada pasien gangguan jiwa. Individu dengan skizofrenia menunjukkan gangguan dalam proses kognitif dan menerima stimulus. Termasuk gangguan memori jangka panjang untuk merespon rasa bahagia, belajar, proses berpikir, membuat keputusan. Kondisi ini sering dihubungkan dengan gejala negatif skizofrenia (seperti anhedonia, asosial) (Green et al., 2019).

Keadaan ini menyebabkan penderita menjadi tidak nyaman dan berpotensi menyebabkan kambuh. Fakta ini menunjukkan bahwa keluarga belum mampu merawat anggota keluarga yang menderita skizofrenia. Keluarga gagal untuk menciptakan dan memodifikasi situasi kondusif yang mendukung pemulihan kondisi pasien selama dirawat di rumah (Fitryasari et al., 2020). Kekerasan merupakan konsekuensi serius dari gangguan jiwa yaitu 2,5 kali lebih besar dibandingkan dengan populasi. Profesional dalam pelayanan kesehatan jiwa menjadi korban kekerasan tiga kali lebih tinggi dari pada dalam pelayanan kesehatan umum (Subu' et al., 2016).

Banyak yang menganggap bahwa orang dengan ganguan jiwa menimbulkan ancaman bagi keselamatan umum. Rasa takut yang dialami perawat akibat kekerasan fisik dapat memengaruhi hubungan perawat dengan pasien, yang menghambat pemberian asuhan keperawatan. Perilaku kekerasan merupakan kejadian umum di Rumah sakit Jiwa. Tenaga kesehatan, sebagian besar perawat, beresiko menjadi korban kekerasan (Subu' et al., 2016).

Berdasarkan survei awal yang dilakukan pada tanggal 11 April 2019 dari hasil wawancara yang dilakukan oleh peneliti terhadap 5 orang perawat, berdasarkan wawancara tersebut didapatkan bahwa 2 orang perawat pernah mendapatkan kekerasan fisik dengan batasan adanya kontak fisik yang dilakukan oleh pasien diantarnya pukulan dan ada perawat yang pernah dilempar dengan mengunakan botol minuman, dan 1 pernah mendapatkan kekerasan pada saat menenangkan pasien amuk yaitu terkena pukul dada, dan 2 orang sering mendapatkan kekerasan non fisik yaitu kata kasar dari pasien serta diludahi oleh 
pasien. Berdasarkan survei awal yang dilakukan oleh peneliti terdapat jumlah perawat yang bertugas di ruang Murai $\mathrm{C}$ sebanyak 17 orang.

Penelitian sebelumnya yang pernah dilakukan adalah untuk melihat pengalaman perawat dalam merawat klien dengan skizofrenia, namun penelitian ini berfokus pada pengalaman perawat yang mengalami tindak kekerasan oleh klien skizofrenia.

\section{METODE PENELITIAN}

Jenis penelitian yang digunakan dalam penelitian ini adalah penelitian kualitatif yaitu suatu jenis penelitian yang bermaksud untuk menjelaskan dan memberi pemahaman dan interprestasi tentang berbagai perilaku dan pengalaman manusia (individu) dalam berbagai bentuk. Informan dalam penelitian ini sebanyak 5 orang perawat yang mengalami tindakan kekerasan oleh klien skizofrenia.

\section{HASIL PENELITIAN}

\section{Bentuk Kekerasan}

Berdasarkan hasil penelitian yang telah dilakukan oleh peneliti mengenai pengalaman perawat apakah pernah mengalami kekerasan yang dilakukan oleh pasien pada saat merawat pasien. Adapun hasil wawancara kepada informan sebagai berikut:

Informan penelitian menjawab bahwa mereka pernah mendapatkan tindakan kekerasan sebagaimana yang dijelaskan oleh informan berikut:

Informan 1

"Pernah, banyak macamnya seperti dipukuli, diludahi"

(wawancara dengan informan Tn.A pada tanggal 16 juli 2019)

\section{Informan 2}

"Pernah, waktu itu saya ditarik- tarik,pernah juga saya dilempar pakai tempat makan" (wawancara dengan informan Ny.A pada tanggal 16 juli 2019)

Informan 3

"Sering ditinju, ditendang dicakar dengan pasien perempuan"

(wawancara dengan informan Tn.H pada tanggal 7 agustus 2019)

\section{Informan 4}

Pernah, lagi bagi obat dipukul dikejar dan saya lari”

(wawancara dengan informan Ny.N pada tanggal 08 agustus 2019)

\section{Informan 5}

"Bentuknya ada dua macam baik itu fisik dan non fisik. Kalau fisiknya dilempar pakai sandal, diludahi. Tapi kalau non fisiknya diancam"

(wawancara dengan informan Ny.Nm pada tanggal 08 agustus 2019)

Berdasarkan keterangan informan di atas, diketahui bahwa kekerasan yang pernah dialami oleh perawat adalah dipukul, ditarik, dilempar menggunakan tempat makan dan juga diludahi, ditinju, ditendang dan dikejar. 


\section{Kondisi Pasien}

Mengenai kondisi pasien ketika melakukan kekerasan kepada perawat. Adapun jawaban dari informan sebagai berikut:

\section{Informan 1}

"Halusinasi lagi timbul, ngoceh- ngoceh sendiri dan ada perintah memukuli bapak" (wawancara dengan informan Tn.A pada tanggal 16 juli 2019)

\section{Informan 2}

"Kondisi fisik sebenarnya sehat tapi kalau untuk kondisi jiwa jelas labil. Dia menyerang saat kita tidak siap"

(wawancara dengan informan Ny.R pada tanggal 16 juli 2019)

\section{Informan 3}

"Rata-rata dalam keadaan kambuh sehingga ada kecenderungan melakukan tindakan kekerasan.Sebenarnya bukan hanya kepada kita saja tetapi kepada sesama pasien juga. Kadang kalau sama kita ketika kita melerai karena mereka tidak menerima dilerai" (wawancara dengan informan Tn.H pada tanggal 07 agustus 2019)

\section{Informan 4}

"Sedang kumat. Kalau tidak kumat kita tidak dipukul"

(wawancara dengan informan Ny.N pada tanggal 08 agustus 2019)

\section{Informan 5}

"Pasien sedang gelisah makanya melakukan kekerasan"

(wawancara dengan informan Ny. Nm pada tanggal 08 agustus 2019)

Berdasarkan keterangan tersebut, kondisi pasien yang melakukan tindakan kekerasan adalah halusinasin nya sedang timbul, pasien sedang labil dan obatnya tidak diminum.

\section{Tindakan Pencegahan}

Adapun tindakan apa yang sebaiknya dilakukan untuk mencegah kekerasan yang dilakukan oleh pasien dijelaskan oleh informan sebagai berikut:

\section{Informan 1}

"Kalau ACC ke dokter jaga langsung di pindahkan ke IPC karena ini termasuk pasien yang gelisah"

(Wawancara dengan informan Tn.A pada tanggal 16 juli 2019)

\section{Informan 2}

"Sama dengan SOP tadi, semua mengacu pada SOP. Itulah satu-satunya cara. Mereka itu labil tidak bisa kita kendalikan"

(wawancara dengan informan Ny.R pada tanggal 1 juli 2019)

\section{Informan 3}

"Yang pertama kita lakukan harus sesuai dengan standar juga dimana kita harus membina karena pasien kalau terhadap perawat yang sudah dia kenal agak kurang melakukan tindakan kekerasan"

(wawancara dengan informan Tn.H pada tanggal 07 agustus 2019) 
Informan 4

"Berlari kabur dari pasien"

(wawancara dengan informan Ny.N pada tanggal 08 agustus 2019)

\section{Informan 5}

"Pemilahan kepada pasien, mana pasien yang termasuk tenang. Melihat keadaan pasien apakah benar dia sudah tenang emosinya sudah stabil itu bisa dipindahkan" (wawancar a dengan informan Ny.Nm pada tanggal 08 agustus 2019)

Berdasarkan keterangan dari informan bahwa tindakan pencegahan terjadinya kekerasan yang dilakukan oleh pasien adalah memindahkan pasien yang gelisah ketemat yang aman dan juga menjaga jarak dengan pasien.

\section{Keadaan Perawat Ketika Mendapatkan Kekerasan}

Adapun keadaan bapak/ibu pada saat mendapatkan kekerasan yang dilakukan oleh pasien dijelaskan oleh informan sebagai berikut:

Informan 1

"Awalnya shok tapi karena ini resiko dan pasien mengalami gangguan jiwa dan adanya rasa ketakutan tetapi sesaat saja"

(wawancara dengan informan Tn.A pada tanggal 16 juli 2019)

Informan 2

"Lumayan sih, waktu itu saya sempat lapor ke komite keselamatan, PPI karena lumayan kan"

(wawancara dengan informan Ny.R pada tanggal 16 juli 2019)

Informan 3

"Yang jelas kita harus menjaga emosi dengan tanpa emosi kita harus bisa mengendalikan emosi pasien karena ketika kita emosi pasti akan terjadi hal-hal yang tidak kita inginkan"

(wawancara dengan informan Tn.H pada tanggal 07 agustus 2019)

\section{Informan 4}

"Baju yang kotor, tidak ada cidera karena hanya dipukul pakai daun"

(Wawancara dengan informan Ny.N pada tanggal 08 agustus 2019)

\section{Informan 5}

"Kalau pasiennya punya riwayat pc . kalau dia ekspresinya sudah tegang dan memukul kita wanti-wanti jangan terlalu dekat dengan pasien. Dia sudah mengancammengancam"

(wawancara dengan informan Ny.Nm pada tanggal 08 agustus 2019)

Berdasarkan keterangan dari informan bahwa mereka awalnya shok dengan adanya tindakan kereasan yang dilakukan oleh pasien tetapi akhirnya mereka menyadari bahwa mereka menjalankan tugas yang pastinya adaresiko karena yang mereka jaga adalah pasien yang mengalami gangguan jiwa. 


\section{Kondisi Kesehatan Perawat}

Kondisi kesehatan perawat selama bekerja di RSKJ Soeprapto tidak ada kendala. Semua perawat sehat wal afiat tanpa kekurangan sesuatu apapun. Mengenai kondisi kesehatan perawat selama berkerja di rumah sakit saat sekarang Berikut penjelasan dari informan:

Informan 1

"Kalau kondisi saat ini sehat dan kondisi sebelumnya kita kena pukul pasti merasakan sakit dan kalau diludahi yang sakit adalah perasaan"

(Wawancara dengan informan Tn.A pada tanggal 1 juli 2019)

\section{Informan 2}

"Alhamdulilah saya sehat. saya memang jarang sakit dan kalau ada kekerasan dari pasien ya namanya resiko pekerjaan saya"

(Wawancara dengan informan Ny.R pada tanggal 16 juli 209)

\section{Informan 3}

"Kalau kondisi alhamdulilah aman- aman saja walaupun ketika ada kekerasan itu kadang ada lecet, kadang juga baju kita robek"

(Wawancara dengan informan Tn.H pada tanggal 07 agustus 2019)

\section{Informan 4}

"Tidak ada yang cidera, tapi kalau bapak yang kamu wawancara tadi pernah cidera" (wawancara dengan informan Ny.N pada tanggal 08 agustus 2019)

\section{Informan 5}

"Terkejut padahal jauh jaraknya pasien didalam dan saya diluar padahal ada trali dan bisa nyampai kekerasan pada saya. Dia melempar. Tapi alhamdulilah sehat- sehat saja"

(Wawancara dengan informan Ny.Nm pada tanggal 08 agustus 2019)

Berdasarkan keterangan dari informan bahwa kondisi kesehatan mereka selama bekerja di RSKJ ini baik-baik saja.

\section{Waktu Pasien Mengamuk}

Pada saat dinas yang mana yang paling sering pasien mengamuk dan beresiko terjadi kekerasan pada saat shift apa siang, malam atau sore. Penjelasan informan sebagai berikut: Informan 1

"Siang dan malam. Kalau pagi ada juga tapi yang pastinya siang dan malam karena petugas lebih sedikit"

(Wawancara dengan informan Tn.A pada tanggal 16 juli 2019)

\section{Informan 2}

"Tidak terpaku pada dinas sore atau malam. Tapi karena pasien yeng memang dalam keadaan labil. Mereka yang tidak minum obat"

(Wawancara dengan informan Ny.R pada tanggal 16 juli 2019) 


\section{Informan 3}

"Sebenarnya kita tidak bisa menentukan kapan dia mengamuk karena pasien ini tidak bisa kita tebak. Kadang pagi tenang tiba-tiba ketika ketemu kita dia kumat tapi kita sebagai petugas harus siap setiap saat"

(wawancara dengan informan Tn.H pada tanggal 07 agustus 2019)

\section{Informan 4}

"Ayuk dinas sore tapi sepertinya dinas sore, ketika bagi obat jam 7 malam"

(wawancara dengan informan Ny.N pada tanggal 08 agustus 2019)

\section{Informan 5}

"Kalau pagi enak karena perawat banyak, tapi kalau sore kami pasti minta bantuan jika ada kekerasan"

(wawancara dengan informan Ny.Nm pada tanggal 08 agustus 2019)

Informan mengatakan bahwa jika mengamuk yang paling sering itu ketika petugas yang berjaga hanya sedikit yaitu waktu sore dan malam hari.

\section{PEMBAHASAN}

\section{Bentuk Kekerasan}

Dari hasil wawancara yang telah dilakukan didapatkan bahwa perawat di RSJKO Bengkulu banyak mendapatkan kekerasan mulai dari kekerasan fisik seperti dipukuli, diludahi, ditarik, dilempari, hingga mendapatkan kat-kata kasar. Sedangkan kekerasan non fisik itu mendpatkan ancaman dari pasien. Pernyataan informan ini sesuai dengan perilaku kekerasan yaitu keadaan dimana seseorang melakukan tindakan yang dapat membahayakan secara fisik, baik pada diri sendiri maupun orang lain, disertai dengan amuk dan gaduh yang tak terkontrol.

Studi oleh Dhasmana et al., (2018) menjelaskan bahwa perlakuan yang diterima tenaga kesehatan ODGJ adalah perlakuan negatif berupa kekerasan fisik atau verbal. Kekerasan fisik berupa memukul, meludah, memercikkan air, melempar benda, dll. Kekerasan fisik adalah perilaku yang menyebabkan lekas marah karena kecemasan yang berlebihan, yang mengarah pada perilaku agresif atau kekerasan. Sementara itu, kekerasan verbal yang sering diterima adalah kata-kata kasar, teriakan dan ancaman dari ODGJ. Perilaku agresif dan kekerasan dapat berkisar dari perilaku mengancam hingga agresi fisik, dan dapat diamati pada pasien dengan berbagai diagnosis, termasuk psikosis organik, penyakit metabolik, penggunaan / penyalahgunaan zat, gangguan kepribadian, gangguan perkembangan, jenis depresi, skizofrenia, dll (Giarelli et al., 2018).

\section{Keadaan Pasien}

Menurut hasil wawancara penelitian ini informan 1 mengatakan jika terjadi halusinasi maka pasien akan berbicara sendiri dan memukuli orang-orang disekitarnya. Sementara itu, menurut orang lain yang akrab dengan masalah ini, jika pasien tidak minum obat, kemungkinan besar pasien memiliki sikap yang tidak stabil dan dapat kambuh sampai terjadi kecelakaan. Penatalaksanaan pertama berupa terapi obat, yang dilakukan dengan pemberian obat antipsikotik kepada pasien, yang membantu menguranginya dengan mempromosikan intervensi terapeutik lain yang membatasi perubahan harga diri dan kurangnya hubungan dengan orang lain (gejala negatif). 
Untuk pengendalian halusinasi dapat dilakukan melalui strategi implementasi yang meliputi menegur 4.444 halusinasi, minum obat secara teratur, berbicara dengan orang lain, dan melakukan kegiatan yang telah ditentukan (Ruswanti \& Pratiwi, 2017). Salah satu cara untuk mengendalikan halusinasi adalah dengan menggunakan obatobatan. Obat-obatan yang biasa digunakan untuk gejala psikologis dan halusinasi penderita skizofrenia adalah antipsikotik. Antipsikotik dibagi menjadi dua jenis: tipikal atau klasik dan atipikal.

\section{Tindakan Pencegahan}

Menurut hasil wawancara dengan narapidana, tindakan pencegahan dilakukan dengan memindahkan pasien yang cemas ke ruang isolasi dan memberikan orientasi kepada pasien. Salah satu tindakan pengobatan atau pencegahan bagi penderita gangguan jiwa adalah dengan menempatkan mereka di bangsal agar perawat merasa lebih aman dalam bekerja. Berdasarkan Permensos RI Nomor 12 Tahun 2018, belenggu merupakan salah satu cara pencabulan terhadap penderita gangguan jiwa, karena penderita gangguan jiwa harus mendapat pengobatan apabila mengalami iritabilitas atau iritabilitas, agar dapat tenang dan kurangi risiko. Deprivasi dapat dicegah karena sebagian besar gangguan jiwa yang dialami mudah diidentifikasi dan risikonya dapat dikurangi dengan penanganan yang baik dan tepat (memadai).

Program kesehatan jiwa harus dimulai kembali untuk meningkatkan penemuan kasus baru pasien dan pelayanan kesehatan jiwa di setiap wilayah (Tristiana et al., 2018). Pentingnya peran serta masyarakat (terutama partisipasi tokoh agama) dan koordinasi lintas sektoral untuk mengatasi pasung dan kebutuhan kesehatan jiwa lainnya harus diperhatikan (Laila et al., 2018).

Petugas kesehatan melakukan sosialisasi pengobatan kesehatan jiwa terhadap ODGJ dan keluarganya, masyarakat dan tatanan lainnya, sehingga masyarakat dapat mulai memahami dan mengenal kesehatan jiwa, dan kemudian menghubungi keluarganya untuk membujuk mereka agar menerima pengobatan formal dan memberikan pendidikan kesehatan untuk meningkatkan kesadaran anda tentang ODGJ dan keluarganya, memahami keluarga dan memberikan motivasi bagi keluarga. Hasil studi menunjukkan bahwa keluarga yang merawat ODGJ memerlukan informasi dan pendidikan kesehatan yang ekstensif agar efektif. Kebutuhan ini mencakup kebutuhan akan informasi yang dapat dipercaya tentang kondisi kesehatan mental, kemungkinan perawatan, sumber daya, dan layanan kesehatan yang tersedia untuk ODGJ dan keluarganya (Rodríguez-Meirinhos et al., 2018).

Sebagian besar keluarga merasa bosan dan putus asa ketika berobat ODGJ dan mulai mengabaikan ODGJ, sehingga penting bagi tenaga kesehatan untuk memberikan dukungan dan motivasi kepada keluarga agar ODGJ dapat sembuh dan kembali ke masyarakat.

\section{Keadaan Perawat}

Berdasarkan hasil wawancara yang dilakukan kelima informan merasa baik- baik saja dan aman. Tapi informan lima pernah hampir mengalami kekerasan yaitu dengan dilempari oleh pasien.

Tindakan kekerasan yang dilakukan pasien dengan gangguan perilaku kekerasan bisa terjadi pada siapa saja, tidak mengenal siapa dan apa objeknya. Pasien yang melakukan tindakan kekerasan tidak akan mempedulikan hak orang lain lagi. Siapapun individu yang terlibat dalam peristiwa kekerasan dapat mengalami tindakan tersebut baik itu perawat, staf 
lain (dokter, psikiater, dan semua yang bertugas diru angan rawat inap), keluarga yang berkunjung, pasien lain yang dirawat dalam satu ruangan dan bahkan bisa merusak lingkungan disekitarnya.

Perawat dalam merawat pasien dengan risiko perilaku kekerasan memiliki risiko besar untuk mengalami tindakan kekerasan dari pasien. Petugas menganggap bahwa tindakan kekerasan yang dilakukan oleh ODGJ adalah hal yang wajar karena mengingat kondisi ODGJ ketika terjadi kekambuhan atau agresif melakukan tindakan di luar kontrol dari ODGJ itu sendiri sehingga petugas kesehatan harus bisa menenangkan (Lestari et al., 2020).

\section{Kondisi Kesehatan}

Berdasarkan hasil wawancara kepada informan bahwa kondisi kesehatan informan sehat wal afiat tanpa kekurangan sesuatu apapun. Dampak yang dirasakan oleh perawat tersebut jika dibiarkan dalam jangka panjang, akan berpengaruh terhadap kualitas pelayanan yang diberikannya. Hal ini dapat terlihat dari sikap perawat yang akan lebih sedikit memberikan waktunya untuk pasien dan juga akan lebih sedikit bertanggungjawab terhadap keperluan pasien skizofrenia.

Satu dari lima informan dalam penelitian ini mengungkapakan mengalami hal yang serupa. Tindakan kekerasan yang dialami perawat ternyata memberikan dampak negatif terhadap pelayanan keperawatan yang mereka diberikan. Perawat dalam memberikan asuhan keperawatan kepada pasien akan timbul kewaspadaan.

\section{SIMPULAN}

Kekerasan yang pernah dialami oleh perawat adalah dipukul, ditarik, dilempar menggunakan tempat makan dan juga diludahi. Kondisi pasien yang melakukan tindakan kekerasan adalah shalusinasi pasien sedang timbul, pasien sedang labil dan obatnya tidak diminum. Tindakan pencegahan terjadinya kekerasan yang dilakukan oleh pasien adalah memindahkan pasien yang gelisah ketemat yang aman dan juga menjaga jarak dengan pasien.

\section{SARAN}

Agar pihak rumah sakit menambah jumlah tenaga perawat karena rasio perawat dengan pasien RSKJ adalah 1:1 agar dalam pelaksanaan perawatan khususnya untuk pasien skizofrenia dapat dilakukan dengan maksimal sehingga tindakan kekerasan tidak terjadi.

Petugas kesehatan di Rumah Sakit Khusus Jiwa Soeprapto agar melakukan pembimbingan kepada pasien skizofrenia dalam membagun komunikasi yang baik dengan orang-orang disekelilingnya agar tidak terjadi tindakan kekerasan.

\section{DAFTAR PUSTAKA}

Andri, J., Febriawati, H., Panzilion, Sari, S. N., \& Utama, D. A. (2019). Implementasi Keperawatan dengan Pengendalian Diri Klien Halusinasi pada Pasien Skizofrenia. Jurnal Kesmas Asclepius (JKA), 1(2), 146-155. https://doi.org/10.31539/jka.v1i2.922

Cheruvu, V. K., \& Chiyaka, E. T. (2019). Prevalence of Depressive Symptoms among Older Adults who Reported Medical Cost as a Barrier to Seeking Health Care: Findings from a Nationally Representative Sample. BMC Geriatrics, 19(1), 192. https://doi.org/10.1186/s12877-019-1203-2 
Dhasmana, P., Singh, G., Srinivasan, M., \& Kumar, S. (2018). Anger and Psychological Well-Being: A Correlational Study among Working Adults in Uttarakhand, India. International Journal of Medical Science and Public Health, 7(4), 296-300. https://doi.org/10.5455/ijmsph.2018.0102802022018

Dinas Kesehatan Kota Bengkulu. (2018). Profil Kesehatan Kota Bengkulu

Fitryasari, R., Nursalam, N., Yusuf, A., \& Hargono, R. (2020). Family Resilience Model Escalating the Family Ability to Prevent Recurrent of Patient with Schizophrenia. International Journal of Psychosocial Rehabilitation, 24(Special Issue 1), 1123-1130. https://doi.org/10.37200/ijpr/v24sp1/pr201259

Giarelli, E., Nocera, R., Jobes, M., Boylan, C., Lopez, J., \& Knerr, J. (2018). Exploration of Aggression/Violence Among Adult Patients Admitted for Shortterm, Acute-care Mental Health Services. Archives of Psychiatric Nursing, 32(2), 215-223. https://doi.org/10.1016/j.apnu.2017.11.004

Green, M. F., Horan, W. P., \& Lee, J. (2019). Nonsocial and Social Cognition in Schizophrenia: Current Evidence and Future Directions. June. https://doi.org/10.1002/wps.20624

Kurniawan, F. (2016). Gambaran Karakteristik pada Pasien Gangguan Jiwa Skizofrenia di Instalasi Jiwa RSUD Banyumas Tahun 2015

Laila, N. H., Mahkota, R., Krianto, T., \& Shivalli, S. (2018). Perceptions about Pasung (Physical Restraint and Confinement) of Schizophrenia Patients: A Qualitative Study among Family Members and Other Key Stakeholders in Bogor Regency, West Java Province, Indonesia 2017. International Journal of Mental Health Systems, 12(1), 35. https://doi.org/10.1186/s13033-018-0216-0

Lestari, W. A. E., Yusuf, A., \& Tristiana, R. D. (2020). Pengalaman Petugas Kesehatan Jiwa dalam Menangani Orang dengan Gangguan Jiwa (ODGJ) di Puskesmas Kabupaten Lamongan. Psychiatry Nursing Jurnal (Jurnal Keperawatan Jiwa), 2(1), 5-15. https://doi.org/http://dx.doi.org/ 10.20473/pnj.v1i1.18589

Riskesdas. (2018). Hasil Utama Riset Kesehatan Dasar. Kementrian Kesehatan Republik Indonesia, 1-100. https://doi.org/https://doi.org/10.1088/17518113/44/8/085201

Rodríguez-Meirinhos, A., Antolín-Suárez, L., \& Oliva, A. (2018). Support Needs of Families of Adolescents With Mental Illness: A Systematic Mixed Studies Review. In Archives of Psychiatric Nursing, 32(1), 152-163). https://doi.org/10.1016/j.apnu.2017.09.004

Ruswanti, R., \& Pratiwi, A. (2017). Upaya Menurunkan Kekambuhan pada Klien Halusinasi Menggunakan Antipsikotik. Universitas Muhammadiyah Surakarta. http://eprints.ums.ac.id/52402/4/Naskah rus.pdf

Subu', M. A., Holmes, D., \& Elliot, J. (2016). Stigmatisasi dan Perilaku Kekerasan pada Orang dengan Gangguan Jiwa (ODGJ) di Indonesia. Jurnal Keperawatan Indonesia, 19(3), 191-199. https://doi.org/10.7454/jki.v19i3.481

Tristiana, R. D., Yusuf, A., Fitryasari, R., Wahyuni, S. D., \& Nihayati, H. E. (2018). Perceived Barriers on Mental Health Services by the Family of Patients with Mental Illness. International Journal of Nursing Sciences, 5(1), 63-67. https://doi.org/10.1016/j.ijnss.2017.12.003 